Article

\title{
Transit Zones, Locales, and Locations: How Digital Annotations Affect Communication in Public Places
}

\author{
Eric Lettkemann * and Ingo Schulz-Schaeffer \\ Institute of Sociology, Technische Universität Berlin, Germany; E-Mails: eric.lettkemann@tu.berlin.de (E.L.), \\ schulz-schaeffer@tu-berlin.de (I.S.-S.) \\ * Corresponding author
}

Submitted: 15 December 2020 | Accepted: 16 April 2021 | Published: 23 July 2021

\begin{abstract}
The article presents an analytical concept, the Constitution of Accessibility through Meaning of Public Places (CAMPP) model. The CAMPP model distinguishes different manifestations of public places according to how they facilitate and restrict communication between urbanites. It describes public places along two analytical dimensions: their degree of perceived accessibility and the elaboration of knowledge necessary to participate in place-related activities. Three patterns of communicative interaction result from these dimensions: civil inattention, small talk, and sociability. We employ the CAMPP model as an analytical tool to investigate how digital annotations affect communicative patterns and perceptions of accessibility of public places. Based on empirical observations and interviews with users of smartphone apps that provide digital annotations, such as Foursquare City Guide, we observe that digital annotations tend to reflect and reinforce existing patterns of communication and rarely evoke changes in the perceived accessibility of public places.
\end{abstract}

\section{Keywords}

annotation; civil inattention; Foursquare; locative media; perceived accessibility; public places; small talk; sociability; social worlds; Tabelog

\section{Issue}

This article is part of the issue "Spaces, Places, and Geographies of Public Spheres" edited by Annie Waldherr (University of Vienna, Austria), Ulrike Klinger (European University Viadrina, Germany) and Barbara Pfetsch (Freie Universität Berlin, Germany / Weizenbaum-Institute for the Networked Society, Germany).

(C) 2021 by the authors; licensee Cogitatio (Lisbon, Portugal). This article is licensed under a Creative Commons Attribution 4.0 International License (CC BY).

\section{Introduction}

Public places are the historical nucleus of the modern public sphere. Scholars have pointed out the importance of public places as sites for encounters where mutual strangers can communicate face-to-face and experience a sense of belonging (e.g., Goffman, 1963; Jacobs, 1961; Lofland, 1998; Sennett, 1977; Strauss, 1961). Gerhards and Schäfer (2010) refer to this earliest and interpersonal level of the public sphere as "encounter publics" (p. 144). Most of the research on encounter publics originated in the pre-digital era. In the wake of digitization, research on interpersonal communication has largely shifted from face-to-face encoun- ters to the "networked publics" (Varnelis, 2008) of social media platforms. However, we believe it is worth taking a fresh look at some older literature. By confronting older concepts on encounter publics with new empirical observations, we expect to gain deeper insights about how profoundly those media have transformed the nature of public places and face-to-face encounters.

Locative media are mobile apps utilizing the positioning features of smartphones to provide their users with web-content about their current position. An example enjoying great popularity is mobile recommendation services that help users find restaurants, shops or other places. In addition to pointing to nearby places, recommendation services provide users with various 
information such as ratings, comments or photos left by other users. In the context of locative media, these various kinds of digital information are usually labelled "annotations" (see Frith, 2015, pp. 81-95). By linking GPS coordinates with user-generated web content, such as photos, reports, or ratings, annotations add digital layers of meaning to urban public places, acting as equivalents of physical display windows, posters, or graffiti. Predicting how the mass proliferation of annotations will change encounters in public places as a whole is difficult. In our empirical research, we narrow our focus on two closely related questions. We investigate how digital annotations affect the perception of accessibility of public places and how this perceived accessibility, in turn, affects communicative patterns in face-to-face encounters.

Accessibility is a concept describing the likelihood that an urban place will provide a social entry point for encounters between strangers (Lofland, 1973, pp. 19-20). Public places are, by definition, legally accessible for every inhabitant or visitor of the city. However, the de facto accessibility of a place is difficult to assess without taking into account the city dwellers' perceptions. As Anselm Strauss (1961, pp. 59-61) has shown, people who belong to different social worlds perceive the accessibility of public places differently. This difference is particularly evident when considering the meeting places of marginalized social worlds, such as those of drug addicts or the homeless. Although these places are legally accessible, many city dwellers avoid them because they attribute a poor reputation to these places. This example also clearly shows that perceptions of accessibility are less a matter of personal experience and more a result of knowledge circulating within social worlds. Many city dwellers know about places to avoid without having personally experienced them. This knowledge also includes the "genres of communication" (Bergmann \& Luckmann, 1995) that are appropriate for addressing strangers in certain places.

Digital annotations have the potential to transform these knowledge-based modes of perceiving accessibility because they provide city dwellers with new channels for creating and sharing knowledge about public places. To investigate this transformative potential, we proceed in two steps. The first part of the article presents the Constitution of Accessibility through Meaning of Public Places (CAMPP) model. This step is necessary to counter the widespread impression that public places are a homogeneous phenomenon in terms of their perceived accessibility. Instead, we develop a typology that distinguishes different types of public places with respect to their perceived accessibility and the way it is constituted by ascription of meaning. In the second part, we discuss how the annotation features of contemporary smartphone apps affect the meaning attached to public places and their corresponding perceived accessibility. In doing so, we employ the CAMPP model as a sensitizing concept.
For the purpose of our discussion, we draw on findings from ethnographic and interview-based research on the use of annotation apps in Berlin and Tokyo. In terms of the use of locative media, Berlin represents a typically European metropolis offering numerous opportunities to study the effect of annotations on the perceived accessibility of public places. To avoid a Eurocentric perspective, however, we added a contrast case. Tokyo is an East-Asian megacity, a characteristic of which is that the various public encounters occur in a spatially condensed form. In addition, our decision for the city was based on Japan's (and especially Tokyo's) reputation as a technologically pioneering society. Considering the spatial condensation of public encounters there, we assumed we would find more creative appropriations of digital annotations in Tokyo than in Berlin, although, with regard to the perceived accessibility of public places, this assumption has not been confirmed.

\section{A Typology of Public Places}

According to Lyn Lofland (1973, p. 19), public places are defined by the criterion of legal accessibility. In contrast to private households or the workplace, public places are, in principle, freely accessible to the urban population. However, only some of them are perceived as equally accessible from the perspective of the members of the different social worlds inhabiting the city. In contrast, many public places, though legally accessible for everybody, are actually visited only by small sections of the urban population. Strauss (1961, pp. 59-67) considers this is a result of urban places being associated with different meanings that attract some social worlds while repelling others. Places gain their meaning from knowledge. This can be general knowledge or more elaborated knowledge shared only within specific social worlds. The concept of 'social worlds' originated in the Chicago School's approach to capturing the segmentation of urban life into relatively independent "universes of discourse" (Strauss, 1993, p. 210). Social worlds organize around core activities concerned, for example, with the production of certain goods or a way of living. Examples from urban life are the worlds of arts, scenes, gangs, sports, or ethnic communities (e.g., Becker, 1982; Irwin, 1977; Whyte, 1943; Zifonun \& Naglo, 2019). Depending on the degree of involvement in a social world's core activities, sociologist David Unruh (1980) distinguished four roles: At the inner circle of social worlds are "insiders" (p. 282) with specialist knowledge. They are the key representatives of this world's lifestyle. Insiders get support from "regulars" (Unruh, 1980, p. 281), who habitually participate in the core activities. At the fringes of social worlds, "tourists," and "strangers" (Unruh, 1980, p. 281) can be found. While tourists are irregular visitors of social worlds who may acquire superficial knowledge, strangers usually stay away. It is one of the peculiarities of urban life that people take on the role of strangers with regard 
to most activities occurring around them (e.g., Lofland, 1973, pp. 3-23).

Social worlds typically have some kind of spatial reference point where participants perform core activities and share knowledge (Strauss, 1993, p. 212). These are the places where insiders and regulars of their respective social worlds are most likely to be found. Usually, members of a social world invest a considerable part of their resources in symbolizing these places as their own. Due to legal accessibility, however, clear demarcations are neither common nor necessary. What is a relevant place for the activities of one social world is very likely to be irrelevant from another world's perspective. Strauss (1961, p. 59) points out that the accessibility of most public places is restricted to some degree simply because these places "lie outside of effective perception" (Strauss, 1961, p. 65) of a large part of the urban population. By filtering out less relevant places, city dwellers cope with the cognitive overload of potentially accessible urban places (e.g., Milgram, 1970). Georg Simmel (1950) once summarized this psychological condition of urban life in the famous social type of the "blasé."

Drawing on the concept of social worlds and their relevance for the perceived accessibility of public places, the CAMPP model distinguishes places according to how strongly they restrict perceived accessibility. The spectrum ranges from places that are actually accessed by all city dwellers to places that are perceived as being accessible only to members of specific social worlds. The model also distinguishes places according to how basic or elaborate the knowledge is that is necessary to participate in the activities performed at these places. The three types of public places we identify this way are associated with different communicative genres (see Figure 1). Communicative genres are established behavioral patterns of-verbal and non-verbal-exchanges helping people to cope with recurring problems of everyday life (Bergmann \& Luckmann, 1995; see also: Goffman, 1981; Hymes, 1974). They are an integral part of a society's knowledge stock. In our case, these communicative genres help people cope with the large number of public encounters they experience in urban environments.

\subsection{Transit Zones}

The transit zones displayed in Figure 1 refer to spaces characterized by a high degree of accessibility, e.g., parking lots, subway stations, or low-budget hotels. These places did not play a significant role in Strauss's (1961) conceptual thinking, but transit zones, as we call them, usually set the stage for Erving Goffman's (1963) observations of "behavior in public places." We have integrated this type into the CAMPP model because transit zones have gained increasing importance for urban life. Cities of contemporary societies are traversed by transit zones, providing infrastructures for the "mobile lives" (Elliott \& Urry, 2010) of the 21st century. At these places, millions of times on a single day people are passing mutual strangers. Transit zones are easily accessible for large numbers of city dwellers because, in the world of mass mobility, it is barely relevant where participants come from or what special knowledge

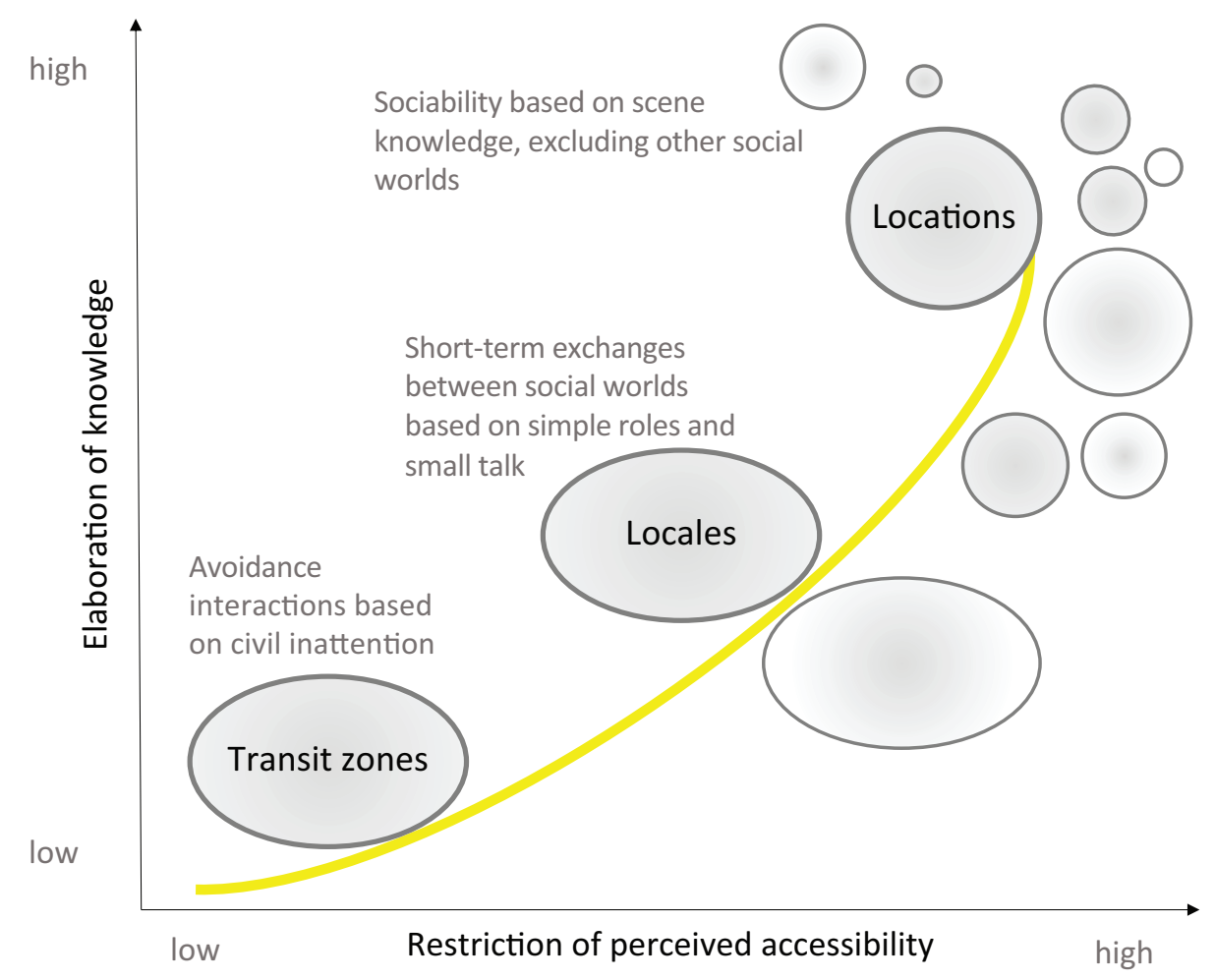

Figure 1. The CAMPP model. 
they have. The knowledge required to navigate transit zones is "general knowledge," i.e., knowledge "routinely transmitted to everyone" (Schütz \& Luckmann, 1973 , p. 312). Most interaction follows the simple rule of avoiding face-to-face conversations. People cope with the co-presence of strangers by applying a behavioral pattern of non-verbal gestures and signals, described by Goffman (1963, pp. 83-88) as "civil inattention." As Anthony Giddens explains, this pattern of nonverbal communication creates an atmosphere of mutual trust among the visitors of public places:

Two people approach and pass one another on a city sidewalk....As the two people approach one another, each rapidly scans the face of the other, looking away as they pass....The glance accords recognition of the other as an agent and as a potential acquaintance. Holding the gaze of the other only briefly, then looking ahead as each passes the other couples such an attitude with an implicit reassurance of lack of hostile intent. The maintenance of civil inattention seems to be a very general presupposition of the trust presumed in regular encounters with strangers in public places. (Giddens, 1990, p. 81)

The rules of civil inattention limit verbal exchanges to a minimum. Special circumstances must prevail for the barriers of civil inattention to be breached-for instance, asking for directions or, broadly speaking, asking for help. The absence of face-to-face conversations turns transit zones into places of anonymity. This anonymity is probably one of the reasons why the participants of mass mobility are hardly aware of being part of one worlddespite the fact that urbanites of the 21st century spend more time moving through transit zones than people have ever before. In the social world of mass mobility, each participant is a stranger to the others and, at the same time, a specialist in this particular field of activities. In other words, there is no meaningful differentiation between the role of the stranger or the insider.

\subsection{Locations}

Compared with that of transit zones, a location's degree of perceived accessibility is low. The concept of locations refers to those places where urban space most convincingly takes the segmented form of "a mosaic of little worlds which touch but do not interpenetrate" (Park, 1915, p. 608). When Strauss (1961, p. 64) wrote about locations, he had in mind public places rooted in urban neighborhoods whose inhabitants are composed of a single economic class or ethnic community. Today, the urban mosaic is completed by post-traditional life forms as, for example, the many worlds of (youth) scenes, such as punks, vegans, computer gamers, skaters, etc. (see Pfadenhauer, 2005). All these social worlds resemble each other in having their own locations, which may emerge around bars, churches, bookstores, gyms, etc.
The prevailing communicative genre at locations is "sociability" (Simmel, 1949). Sociability is a playful pattern of exchange between people, "always contingent on the joy of others" (Simmel, 1949, p. 257), which might be expressed in joint activities, such as drinking beer or playing cards, but above all in face-to-face conversations (Oldenburg, 1997, pp. 26-31). Although most locations are legally accessible to the general public, the public display of sociability is, quite often, an expression of a social world's dominance over a place that keeps outsiders away. Consequently, those public places, where sociability is most likely to occur, bring together especially those urbanites who share a common lifestyle and common activities.

Participating in the activities that take place at locations often requires elaborate knowledge. As visiting a location is often about sharing special knowledge and cultivating particular lifestyles, people can easily distinguish insiders and regulars from occasional tourists and strangers. Referring to the example of a Polish tavern in 1960s Chicago, Strauss (1961) points out that, at a location, "the stranger is quickly spotted" (p. 64) due to their lack of special knowledge in how to participate in the core activities that regular visitors perform at the location. Most strangers avoid such locations because they are unfamiliar with the activities carried out there. They feel uneasy as they do not know what goes on and how to address other people. Considerable intimacy with subcultural codes and respective lifestyle practices is necessary to gain knowledge of a social world's meeting points and to understand its symbolic forms of expression. This is as true for the visitors of a present-day techno club in Berlin as it was for those of a Polish tavern in 1960s Chicago.

\subsection{Locales}

Navigating public places such as city plazas, concert halls, shopping promenades, sports facilities, or parks and participating in the typical activities taking place there usually requires more specific knowledge than navigating transit zone but less knowledge than that required to feel comfortable at the locations of specific social worlds. In these places, "the diversity of the city's residents comes together and dwells side by side, sometimes appreciating one another, entertaining one another, or just chatting, always to go off again as strangers" (Young, 1986, p. 21). Strauss (1961, p. 63) summarizes these places, where people experience the diversity of social worlds, under the heading of "locales." While locations are associated with one dominant way of life, locales attract people of very different lifestyles. For an example, Strauss refers to a street in Chicago once famous for its vibrant nightlife:

It is one of the glamour streets of Chicago. There one can see, if one has an eye for them, prostitutes, pimps, homosexuals, bisexuals, upper class men and women, university students, touts, artists, tourists, 
business men out for a good time with or without girlfriends, young men and women dating, people of various ethnic backgrounds, policemen, cabbiesthe entire catalogue is much longer. Rush Street is a locale where people from many different urban worlds, with many styles of urbanity, pass each other, buy services from each other, talk to one another, and occasionally make friends with one another. (Strauss, 1961, p. 63)

Locales are the spatial intersections of the orbits of people who, most of their lifetimes, are committed to different urban worlds (Strauss, 1961, p. 64). The exchanges taking place at locales are coordinated using simple role sets such as marketers and customers, allowing strangers to temporarily breach the barriers of civil inattention without their identities being affected. Accordingly, face-to-face conversations in locales rarely lead to social relations that go beyond small talk. As Judith Beinstein $(1975$, p. 147) points out, small talk is a "highly ritualized and predictable" genre of communication "to initiate exchanges, pass time effortlessly, and maintain cordiality around acquaintances and strangers." Both components, ritualization and predictability, are social means to prevent from having to open "to each other's potential disapproval" (Beinstein, 1975, p. 148). Thus, small talk is appropriate at locales, "where social heterogeneity and secondary contacts proliferate" while "establishing mutual trust [is] especially difficult" (Beinstein, 1975, p. 148).

\section{Locative Media and Digital Annotations of Public Places}

Strauss' (1961) reflections on public places, on which the CAMPP model is based, still assume that the ascriptions of meaning and the corresponding perceived accessibility of places are primarily generated in face-to-face interaction. Of course, Strauss was also aware of the fact that life in modern cities has always been permeated by media technologies such as telephone booths, billboards, or newspapers, which provided the urban population with information and connected them. Nevertheless, in his conceptual reflections, these media technologies do not play a major part. In an age of "deep mediatization" (Couldry \& Hepp, 2017), this way of conceptualizing the perception of public places no longer seems adequate. Media technologies always had an impact on the meaning attributed to public places. Whether people perceive Alexander Platz in Berlin, for example, as a crime-ridden location or as a touristic locale depends largely on the discourses taking place in the mass media and on Internet platforms. There is reason to assume that, with the development of web-enabled smartphones, the impact of digital media will even increase, as smartphone apps directly intervene in face-to-face communication on public places (Rainee \& Zickuhr, 2015).

The CAMPP model is intended to serve as a "sensitizing concept" (Blumer, 1954) for investigating how loca- tive media, a new type of smartphone app, affect the perceived accessibility of urban public places. "Locative media" is an umbrella term for mobile apps utilizing the positioning features of web-enabled smartphones to provide users with digital information about their physical and social surroundings (see Frith, 2015, p. 2). Locative media take the mediatization of urban environments to a new level by merging the digital representation of a place with its physical reference on a smartphone screen. In the words of media scholar Adriana de Souza e Silva (2006), these apps create a "hybrid space" composed of physical and digital experiences. Mobile games that project digital creatures into physical places or navigation services that guide their users in realtime through unknown streets are examples of different locative media. In this article, we take a closer look at another locative media, annotation-based recommendation apps.

The idea of annotating public places arose in the 2000s within locative media art projects (Tuters \& Varnelis, 2006). The original aim was to initiate public encounters and to re-write the dominant meanings associated with public places in creative and playful ways (e.g., Farman, 2014; Liao \& Humphreys, 2014). However, it has not been locative media art but commercial recommendation apps that have made annotating an everyday practice suitable for the masses of smartphone users (e.g., Wilken, 2019). Thus, commercial recommendation services are the research object of our investigation. To trace their effects on perceptions of spatial accessibilities, we conducted and analyzed in-depth interviews and media diaries of 15 users residing in Germany and 17 users residing in Japan. A translator assisted us with the Japanese interviews. The empirical research was conducted in two cities that offer a broad spectrum of diverse public places: Berlin and Tokyo. The interviews with users in Berlin took place in summer 2018; those with users in Tokyo in fall 2019. On average the interviews lasted 60 minutes. They covered topics of leisure activities, navigating the city, practices of finding a place, and digital media use. Each interview was preceded by two to four weeks in which interviewees kept a "media diary" (Berg \& Düvel, 2012) about their app use based on screenshots and brief descriptions of their spatial perceptions; these diaries later served as conversational stimuli for the interviews. All interviews were recorded, transcribed and coded. Coding was performed according to the principles of Grounded Theory and with the help of a software tool for qualitative content analysis (MAXQDA) to systematically capture all interview statements about relationships between spatial perception and digital annotations. In line with Grounded Theory's core principle of "theoretical saturation" (Strauss, 1987), the aim of coding the interview transcripts and media diaries was to draw a picture, as complete as possible, of the different ways in which recommendation apps affect the spatial perceptions of the users in the two cities. 
In Germany, we interviewed users of the Foursquare City Guide. Foursquare is one of the world's leading recommendation apps for restaurants, shops, and other places (see Frith, 2015, pp. 96-111; Wilken, 2019, pp. 67-75). In Japan, we focused on Tabelog, which is the more popular app there. Though our focus was on these two apps, the interviews also included information about other locative media that are part of users' media ecology for navigating their cities. In contrast to Foursquare, Tabelog is specialized on restaurants and other eating places. Yet, both apps are similar in their functions. Unlike desktop software, these apps are designed to be used on the go, for example, while riding the subway or just before entering an unknown location. Users can search for places in their vicinity using digital maps and lists they can sort by categories, ratings, or keywords. User-generated content such as photos, short reports, and ratings provide them with various information about places. Heavy users are also eager to write their own reports, rate places, and share photos. Since we were interested in the ways annotated recommendations affect the perceptions of spatial accessibilities, we relied primarily on interviews, and we left aside a detailed content analysis of the two apps at this point. Inspired by the "walkthrough method" (Light et al., 2016), we conducted a content analysis of Foursquare's interface and describe it in another article (Lettkemann \& Schulz-Schaeffer, in press). For the purpose of this article, however, we consider it sufficient to show some screenshots depicting essential interface elements of both apps (see Figure 2). These screenshots show typical search results, such as text-based recommendations, photos, maps, and ratings.

We discuss our observations along the three types of public places described in the CAMPP model. Since the Japanese app Tabelog is limited to places that we classify as locations, we can compare the uses of Foursquare and Tabelog only with respect to locations. Nevertheless, since these apps are typically used in combination with other social and locative media, our interview data from Tokyo and from Berlin also provide information about the other types of public places. For the purpose of this article, we concentrate on these two apps so that the examples of interview quotes that refer to locales and transit zones are taken only from our case study in Berlin. In our analysis, we find three practices of using annotations, two of which do not increase the perceived accessibility of public places, while the last one helps to overcome barriers, at least temporarily.

\subsection{Reflecting Place-Related Knowledge}

Transit zones are characterized by a high degree of perceived accessibility but also by anonymity. Some older studies on locative media assumed that transit zones such as subway stations or airports gain symbolic significance just because users tend to annotate them quite often (e.g., Buschauer \& Willis, 2013, p. 33). However, do these annotations really add new layers of meaning to transit zones? Our empirical material suggests otherwise. The prevalent form of annotating transit zones seems to be to share basic knowledge relevant to the activities of mass mobility. The following quote from an interview with a German heavy user about helpful information, called a "tip" in the Foursquare app, illustrates this point:

\section{Q: When do you write a tip?}

A:... At Berlin Hauptbahnhof, I will not write a tip. Except maybe.... I think I once wrote a tip because at some point... that may not be the case anymore, but in the past, you hardly found any lockers in the main hall or they were all occupied.
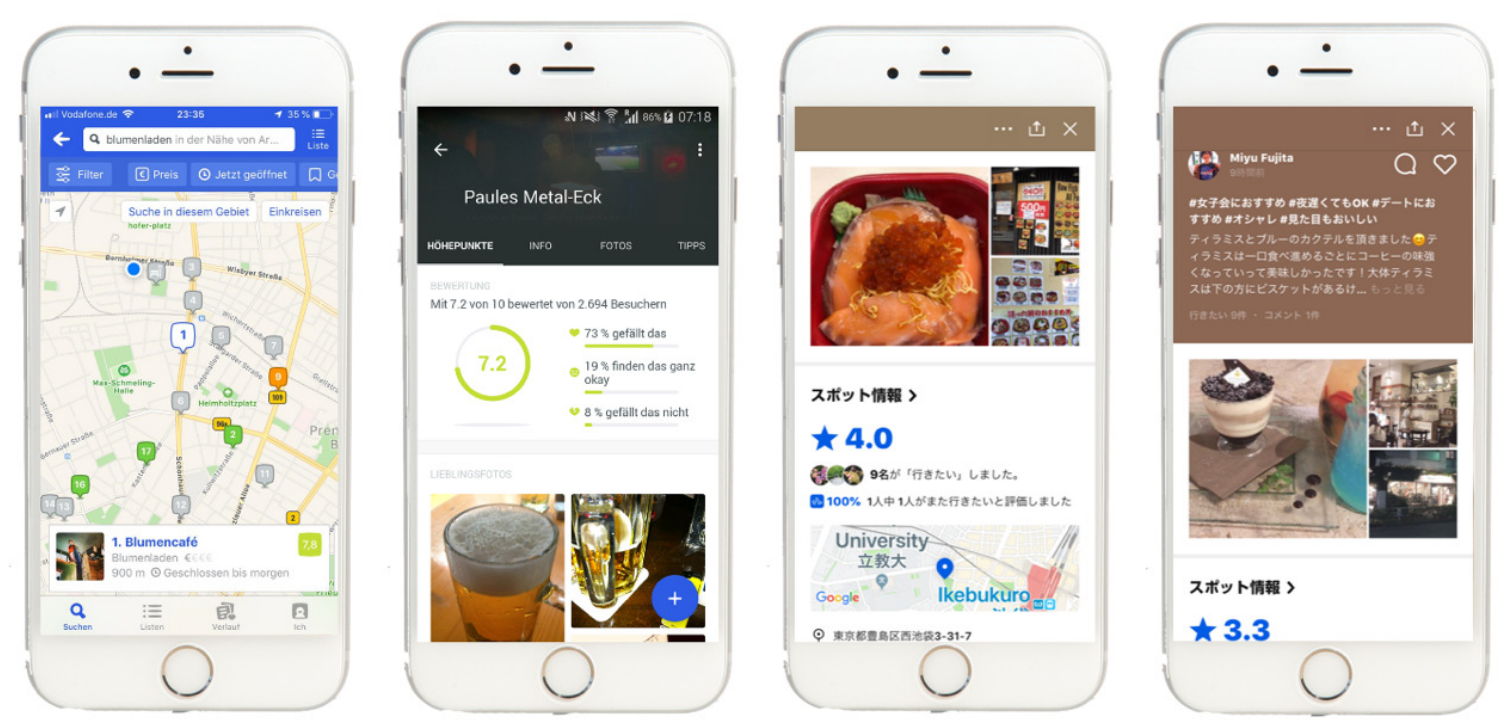

Figure 2. Screenshots of Foursquare City Guide (left) and Tabelog (right) captured in our interviewees' media diaries. 
Q: This tip is very helpful; it was displayed on my phone once! (Laughter).

A: And then at some point in time they built this luggage center... between these two tracks where you could just drop off your luggage for 5 Euros without having to search for a locker for a long time. This knowledge is of great a help in such a large building!" (Foursquare user, insurance agent, male, 43 years)

All the statements of our interviewees regarding transit zones have one thing in common. The knowledge objectified in annotations that focus on transit zones usually provide tips and tricks for coping with the burdens of urban life's mobility. In other words, annotations referring to finding lockers, rare consumer goods, WiFi passwords, restrooms, and similar instances relieve people of the unpleasant burden of asking strangers. Consequently, face-to-face interactions are further minimized, reinforcing the communicative pattern of civil inattention predominant in transit zones. This way of annotating knowledge makes it easier for strangers to move through unknown transit zones, but it does not change the symbolic meaning of this type of public place.

With locales, we also observe that the annotations tend to reproduce and reinforce place-related patterns of communication and attributions of meaning. Foursquare annotations referring to locales often display the kind of knowledge that corresponds with the typical tropes of small talk. For instance, the content about Berlin's Kollwitzplatz, a popular locale to stroll and go out to, includes a variety of comments written in the style of small talk: Typical topics for small talk are addressed, ranging from warnings about too high prices to various recommendations on how visitors can pass the time (see Figure 3). Since Kollwitzplatz is also a tourist hotspot, many of the comments are written in English. As is characteristic in verbal small talk, these comments are a series of short statements that are little or not at all related to each other and offer little potential for disapproval.

One reason to read the annotated recommendations related to locales is to find places whose atmosphere lends itself as a background for photos that can be shared on Instagram, TikTok, and other social-media platforms. This reason was mainly brought up by our younger interviewees. Since they assigned themselves to heterogeneous urban scenes, ranging from regular visitors of sports bars to nature lovers, this concordance can be read as an indication of the continuing aesthetic appeal of these places to heterogeneous social worlds.

\subsection{Filtering Out Locations}

Since the more elaborated knowledge required to understand what is going on at locations restricts their perceived accessibility, the question arises whether the information shared by users of recommendation apps can reduce these barriers to perceived accessibility. Although users can search for all kinds of places in their surrounding areas, including those different from their usual habitat, our interviews show that this kind of search is rare. The main motivation to use recommendation apps seems to be to find additional places that fit existing preferences rather than to explore unknown territory. Instead of the internalized psychological filters Milgram (1970) or Simmel (1950) have attested to urbanites, users of recommendation apps allow external technical filters to relieve them of the cognitive overload of potentially accessible places. The various filtering features of Foursquare and Tabelog make it possible for users to exclude from searches most kinds of places and

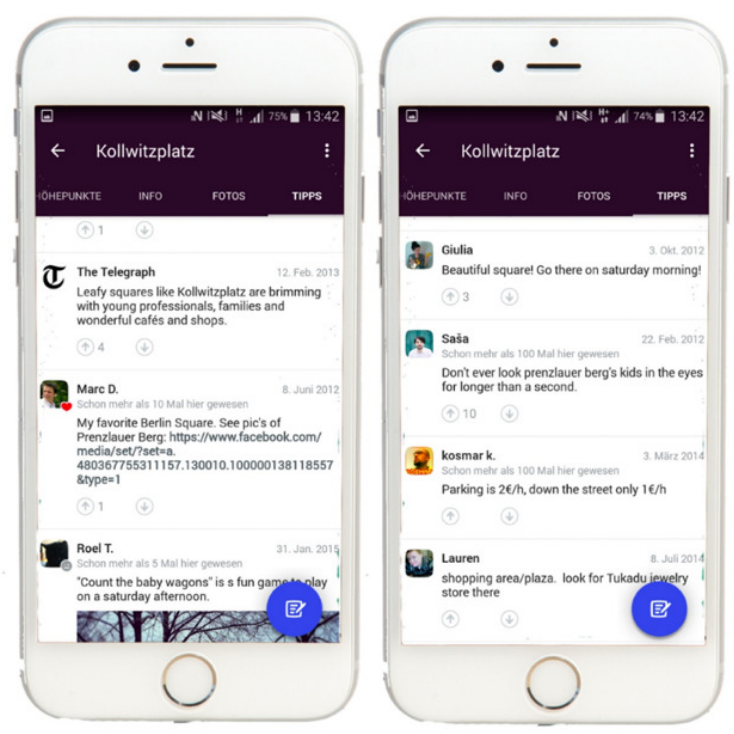

Figure 3. Berlin's Kollwitzplatz through the lens of Foursquare City Guide. Note: screenshots captured during our case study. 
to include only those with particular characteristics. For example, a young management consultant without an office of his own, who does much of his work in cafés in downtown Berlin, reported that he rarely visits any places that do not match his search criteria. Cafés without free WiFi or enough sockets to charge his laptop are useless places to him:

I have my search criteria for a place where I want to work [sockets, free WiFi, etc.]. I don't change these criteria very often. In the end, I always end up in relatively similar places because the criteria that I am basically looking for on Foursquare are the same criteria that I have implicitly always been looking for. (Foursquare user, business consultant, male, 26 years)

Most of our interviewees reported similar search strategies. A Japanese business student told us that she is always looking for quiet and inexpensive bars where she can have long conversations with her friends. Her fellow student is mainly interested in finding places where credit card payment is accepted. A web-developer from Berlin reported that, during her lunch breaks, she is always looking for highly rated cafés that serve certain brands of coffee. Most interviewees confirm that they look for places that fit their own lifestyle. Discovering unfamiliar places and exploring unknown social worlds at their locations does not seem to be a pronounced motive to use Foursquare or Tabelog. This is remarkable in that the advertising texts of both apps promise potential users that installing the app will give them access to new places and experiences. The Japanese and German users in our sample do not show any significant difference in this respect. One of the few differences is that, in some instances, the apps offer users different search categories.

Users in Berlin and Tokyo agree that the most important source of information to decide whether a location corresponds to their own preferences is viewing the annotated photos of the locations. With these photos, users communicate their world-specific knowledge about taste, fashion, etc. Thus, visual annotations of locations also tend to reflect already established views rather than assign new meanings to public places. One Japanese interviewee even told us that he completely forgoes reading comments and makes his decision solely on the basis of photos, which he considers more authentic than written reports of other guests' experiences:

When I look at the photos, I can decide for myself, does that food look tasty, or does that setting look appealing? And I don't really believe in written comments because it is a very individual feeling whether something tastes delicious or whether you like the interior, and so on. And from the photos, you can see much more because you can judge for yourself, does it look tasty, or does this store look good, and so on. (Tabelog user, business student, male, 21 years)
Though the users most of the time employ quite restricted search strategies, they describe themselves as curious to get to know new places. This is not a contradiction. Annotation apps accomplish the trick of satisfying the desire of many users for the experience of new places without exposing these users to the risk of disappointment or irritation that comes with random exploration of public places. Our tentative conclusion is therefore: Even though it is highly likely that using recommendation apps increases mobility across urban public space, perceived accessibility to locations seems to be unchallenged. Most users remain within the borders of their social worlds.

Even if users are looking for different places, the problem arises that only small pieces of scene knowledge are portrayed in annotations. Places are not only technically filtered by searching users selecting certain search categories; rather, the filtering process starts a long time before, with the social composition of those people who create annotations. Those heavy users, who actively annotate places, are probably representatives of a small number of social worlds, as one of our interviewees explained after exploring her neighborhood through the Foursquare lens. She lives in Wedding, one of Berlin's districts with a high percentage of people of Turkish origin:

Q: Do you think this is a realistic reflection of your neighborhood?

A: Well, I haven't lived here that long now, so I can't judge that. I think there were far too few kebab shops suggested to me for me to be in Wedding. (Laughs).

Q: Okay. (Laughs).

A: Here there are very many kebab shops, and you simply notice that here about 50 percent at least or no, 30 percent of the people somehow have something to do with Turkey. When I look at reality and Foursquare, then Foursquare seems a bit too European to me.

Q: Okay. How would you describe the picture that Foursquare shows, European, and maybe some other attributes that come to mind?

A: European, progressive, creative and also a bit green, that's it. (Foursquare user, chemistry BA student, female, 21 years)

\subsection{Touristic Visits to the Locations of Neighboring Social Worlds}

However, our sample is not so homogeneous that we cannot point out some opposing tendencies. Some interviewees have described annotations as "windows" allowing them to look behind the walls of unknown locations. That knowledge does not necessarily mean they actually visit a place, but social barriers seem to 
be lowered. A Japanese interviewee described a situation when she arrived at a small train station and there was only one store available that she normally would not have entered:

I found [the store] a bit strange because the only staff member was a guy who was reading the newspaper. I wondered: $\mathrm{Hm}$, is this store even open? And the store looked very old. And it wasn't a chain store, it was run by a single person, and it felt a bit difficult for me to get in. It didn't look inviting. But the [Tabelog] reviews were good and it said in the reviews that the coffee was really tasty and there were a lot of reviews of it. And then I said to myself: Pull yourself together and I went in. I was very hungry at the time. (Tabelog user, business student, female, 21 years)

In situations where only a limited number of places are available or when users decide to drift through unknown streets, they consult annotations of locations that usually fall outside their search categories. The fact that the majority of users share similar lifestyles might be quite functional in the sense that it makes it easier to trust other users' recommendations and taste judgements. A similar effect can be observed with regard to the rating scores of locations, calculated from users' likes and numbers of visits. According to some interviewees, their trust in ratings occasionally leads them to places they would never have chosen based on the self-presentation of these locations; as a German interviewee reported about a situation where he was looking for pancakes:

[I entered] a restaurant that looked like a rocker bar from the outside. I probably wouldn't have entered it. But from the inside it looked like my grandma's living room and there were delicious pancakes! (Laughing). Usually, I would never have entered, really, but I had based my decision on the score. (Foursquare user, tax consultant, male, 37 years)

In all instances reported to us, these excursions remained short, but without the help of annotations they probably would not have occurred at all. In other words, annotations make it easier for strangers to take on the role of tourists venturing into neighboring worlds. It is an open question whether the new kind of "touristic gaze" (Urry \& Larsen, 2011) that annotation apps cast on public places will lead to changes in the perceived accessibility of places in the long run. For the moment, it seems that scene-specific forms of sociability, such as listening to loud rock music, impel outsiders to withdraw to their own social worlds after their touristic desire for an exotic experience has been satisfied.

\section{Conclusion}

The CAMPP model is built on the basic assumptions of interactionist urban sociology as laid out by
Strauss (1961). It extends and refines these basic assumptions by adding another type of public place, transit zones, and by linking types of public places to research on scene knowledge and communicative genres. In this way, it allows three different types of public places to be distinguished based on the empirical characteristics of perceived accessibility, forms of knowledge, and patterns of communication. The different ways in which transit zones, locales, and locations are rendered meaningful is related to these three characteristics. Locative media provide an additional option to attach meaning to public places. Yet, we know little about the consequences of this new form of mediatizing public places. The CAMPP model is intended to serve as an analytical tool to trace these effects.

The research on Foursquare City Guide and Tabelog, presented in this article suggests that digital annotations tend to reflect and reinforce the given views and interpretations of public places. The information provided by annotations usually contains the kind of knowledge and the pattern of communication already established for the respective transit zone, locale, or location. And the users of the recommendation apps tend to use the information as a support for their already established ways of navigating the city. The two apps are not only similar in terms of interface design but also in the ways users, residing in Tokyo and Berlin, appropriate the annotation features of both apps. In the case of locations, annotations constantly provide mobile users with suggestions and thus succeed in satisfying their need to discover new locations. Yet, these suggestions are similar enough to the users' already preferred locations to shield them from experiencing the risks and irritations associated with random exploration. Personalized search filters and algorithmically generated location recommendations in connection with the described user practices maintain the established restrictions of perceived accessibility of public places by directing users to places that correspond to their social and environmental preferences.

Our results diverge in interesting ways from older works on the appropriation and impact of digital annotations on public places. For instance, ethnographic studies on the field of locative media art emphasized that annotations are used to challenge and change established meanings of public places (e.g., Farman, 2014; Liao \& Humphreys, 2014; Tuters \& Varnelis, 2006). In technical terms, these locative media art projects operate in similar ways to recommendation services developed in commercial contexts. Although theoretically imaginable, the users of Foursquare and Tabelog we met in our research do not annotate places in order to challenge their meanings. This creative restraint is explained by how these apps are intended to be used and how they are actually used. Those heavy users of Foursquare, Tabelog, and similar recommendation services who actively annotate places share this information to describe these places as they present themselves to them. The subject of their annotations is the given meaning of a place as they 
experience it. Likewise, the more occasional users of these apps are looking for reports and photos to gain information about the given meaning of a place. Thus, in contrast to a locative media art project that, for instance, turns an exterior wall into a projector screen, employing annotation to give a place a new meaning would make not much sense in this context.

It was, however, not apparent from the outset that providing and searching for information about places would become the main way of using these recommendation apps. In an early study on Foursquare, Jordan Frith (2013) observed a pattern of use in which using Foursquare was much more about exploring a wide range of unfamiliar places than about making sure that the places to be visited would match with own preferences. Frith explained this behavior by the gamified design of the app, rewarding visits to new places with digital badges, etc. Since 2014, however, the company owing Foursquare has removed these gamified elements from the main app to focus more on its spatial search and recommendation features (Frith, 2015, pp. 96-111; Lettkemann \& Schulz-Schaeffer, in press), thus taking into account the now dominant way to use these kinds of recommendation apps. Nevertheless, there is reason to believe that gamified elements of locative media have some potential in influencing their users' perceptions of public places. For this reason, a next step in our research will be to compare the effects of digital local recommendations with those of locative games. Locative games, such as the popular Pokémon Go, transform public places into playgrounds and attract a broader spectrum of social worlds. Thus, they may have a greater potential to change how people navigate and perceive the urban public sphere.

\section{Acknowledgments}

We acknowledge support from the German Research Foundation (DFG, Deutsche Forschungsgemeinschaft)project number 290045248, SFB 1265 . We also acknowledge Technische Universität Berlin for paying this article's processing charge from its publication fund for openaccess-journals. We thank the participants of a study group meeting of the Japan Society of Information and Communication Research (JSICR) at Kansai University in Osaka for their valuable input. We thank our student assistants Lukes Collin, Nina Meier, and Johanna Weirauch for supporting the empirical research and participating in conceptual discussions. We are especially grateful to JSICR members Keita Matsushita and Yonnie Kim for helping us to organize the interviews in Tokyo. We thank our interpreter in Tokyo, Franziska Schultz, for her assistance.

\section{Conflict of Interests}

The authors declare no conflict of interests.

\section{References}

Becker, H. S. (1982). Art worlds. University of California Press.

Beinstein, J. (1975). Small talk as social gesture. Journal of Communication, 25(4), 147-154.

Berg, M., \& Düvel, C. (2012). Qualitative media diaries: An instrument for doing research from a mobile media ethnographic perspective. Interactions, 3(1), 71-89.

Bergmann, J. R., \& Luckmann, T. (1995). Reconstructive genres of everyday communication. In U. Quasthoff (Ed.), Aspects of oral communication (pp. 289-304). De Gruyter.

Blumer, H. (1954). What is wrong with social theory. American Sociological Review, 19(1), 3-10.

Buschauer, R., \& Willis, K. S. (2013). Introduction. In R. Buschauer \& K. S. Willis (Eds.), Locative media: Multidisciplinary perspectives on media and locality (pp. 24-45). Transcript.

Couldry, N., \& Hepp, A. (2017). The mediated construction of reality. Polity Press.

de Souza e Silva, A. (2006). From cyber to hybrid: Mobile technologies as interfaces of hybrid spaces. Space and Culture, 9(3), 261-278.

Elliott, A., \& Urry, J. (2010). Mobile lives. Routledge.

Farman, J. (Ed.). (2014). The mobile story: Narrative practices with locative media. Routledge.

Frith, J. (2013). Turning life into a game: Foursquare, gamification, and personal mobility. Mobile Media \& Communication, 1(2), 248-262.

Frith, J. (2015). Smartphones as locative media. Polity Press.

Gerhards, J., \& Schäfer, M. S. (2010). Is the internet a better public sphere? Comparing old and new media in the USA and Germany. New Media \& Society, 12(1), 143-160.

Giddens, A. (1990). The consequences of modernity. Polity Press.

Goffman, E. (1963). Behavior in public places: Notes on the social organization of gatherings. Free Press.

Goffman, E. (1981). Forms of talk. University of Pennsylvania Press.

Hymes, D. (1974). Ways of speaking. In R. Bauman \& J. Sherzer (Eds.), Explorations in the ethnography of speaking (pp. 433-451). Cambridge University Press.

Irwin, J. (1977). Scenes. Sage.

Jacobs, J. (1961). The death and life of great American cities. Random House.

Lettkemann, E., \& Schulz-Schaeffer, I. (in press). Annotating places: A critical assessment of two hypotheses on how locative media transform urban public places. In A. Million, C. Haid, I. Castillo Ulloa, \& Nina Baur (Eds.), Spatial transformations. Routledge.

Liao, T., \& Humphreys, L. (2014). Layar-ed places: Using mobile augmented reality to tactically reengage, reproduce, and reappropriate public space. New Media \& Society, 17(9), 1418-1435. 
Light, B., Burgess, J., \& Duguay, S. (2016). The walkthrough method: An approach to the study of apps. New Media \& Society, 20(3), 881-900.

Lofland, L. H. (1973). A world of strangers: Order and action in urban public space. Basic Books.

Lofland, L. H. (1998). The public realm: Exploring the city's quintessential social territory. Transaction Publishers.

Milgram, S. (1970). The experience of living in cities. Science, 167(3924), 1461-1468.

Oldenburg, R. (1997). The great good place: Cafés, coffee shops, bookstores, bars, hair salons and other hangouts at the heart of a community (2nd ed.). Da Capo Press.

Park, R. E. (1915). The city: Suggestions for the investigation of human behavior in the city environment. The American Journal of Sociology, 20(5), 577-612.

Pfadenhauer, M. (2005). Ethnography of Scenes: Towards a Sociological Life-world Analysis of (Post-traditional) Community-building. Qualitative Social Research, 6(3), Article 43. https://doi.org/10.17169/fqs-6.3.23

Rainee, L., \& Zickuhr, K. (2015). Americans' views on mobile etiquette. Pew Research Center. https:// www.pewresearch.org/internet/2015/08/26/ americans-views-on-mobile-etiquette

Schütz, A., \& Luckmann, T. (1973). The structures of the life-world, Volume I. Northwestern University Press.

Sennett, R. (1977). The fall of public man. Alfred A. Knopf.

Simmel, G. (1949). The sociology of sociability (E. C. Hughes, Trans.). American Journal of Sociology, 55(3),
254-261.

Simmel, G. (1950). The metropolis and mental life. In K. H. Wolff (Ed.), The Sociology of Georg Simmel (pp. 409-420). Free Press.

Strauss, A. L. (1961). Images of the American city. Free Press.

Strauss, A. L. (1987). Qualitative analysis for social scientists. Cambridge University Press.

Strauss, A. L. (1993). Continual permutations of action. de Gruyter.

Tuters, M., \& Varnelis, K. (2006). Beyond locative media: Giving shape to the Internet of Things. Leonardo, 39(4), 357-363.

Unruh, D. R. (1980). The nature of social worlds. The Pacific Sociological Review, 23(3), 271-296.

Urry, J., \& Larsen, J. (2011). The tourist gaze 3.0. Sage.

Varnelis, K. (2008). Networked publics. MIT Press.

Whyte, W. F. (1943). Street corner society: The social structure of an Italian slum. University of Chicago Press.

Wilken, R. (2019). Cultural economies of locative media. Oxford University Press.

Young, I. M. (1986). The ideal of community and the politics of difference. Social Theory and Practice, 12(1), $1-26$.

Zifonun, D., \& Naglo, K. (2019). Core activity, event and crisis: Making the small worlds of amateur football: Moving the social. Journal of Social History and the History of Social Movements, 61(1), 61-82.

\section{About the Authors}

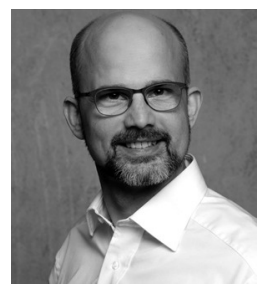

Eric Lettkemann is a Postdoctoral Researcher at the Institute of Sociology at the Technical University of Berlin. His main fields of work are science and technology studies (STS), digital media, urban sociology, sociology of knowldge, and qualitative research methods. Currently, his focus is on the impact of the mediatization of public places on urban life. He is a member of a research project investigating how users of locative media perceive the accessibility of urban places.

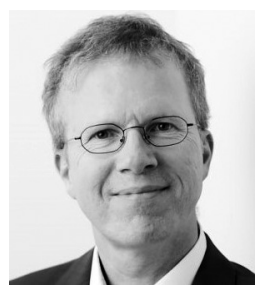

Ingo Schulz-Schaeffer is Professor of sociology at the Technical University of Berlin. He is a member of the program committee of the Priority Program 2267 "Digitalization of Working Worlds," a Principal Investigator of the Collaborative Research Centre 1265 "Re-figuration of Spaces," and a Principal Investigator of the Cluster of Excellence "Science of Intelligence." His recent empirical research includes locative media and how they change urban space, reward-based crowdfunding as gift exchange, and the social construction of human-robot collaboration via prototype scenarios. 